\title{
Технологии внутреннего монтажа бескорпусных элементов и особенности проектирования микросистем со встроенными кристаллами
}

\author{
Часть 1
}

УДК 658.512 | ВАК 05.27.06

\author{
Д. Вертянов ${ }^{1}$, С. Евстафьев ${ }^{2}$, П. Виклунд ${ }^{3}$ В. Сидоренко ${ }^{4}$
}

\begin{abstract}
Технологии 3D-интеграции на уровне печатной платы и корпуса микросхемы по методу внутреннего монтажа бескорпусных элементов помогают решить задачу миниатюризации сложно-функциональных устройств. В отличие от традиционного подхода - уменьшения геометрических размеров компонентов на печатной плате, технология внутреннего монтажа позволяет сделать огромный скачок в увеличении плотности компоновки и реализовать изделия, которые обычными методами создать просто невозможно. В статье представлен обзор технологий и конструктивно-технологических решений для внутреннего монтажа бескорпусных элементов в структуру подложки корпусов микросхем и печатных плат, рассмотрены проблемы и способы их решения в процессе реализации проекта со встроенными активными и пассивными элементами, выполненного с помощью САПР компании Mentor, A Siemens Business.
\end{abstract}

\section{ВВЕДЕНИЕ}

Компании-разработчики электронных устройств стремятся вместить всё больше функционала в меньший объем. Для реализации этой задачи производители электронных компонентов продолжают уменьшать габариты выпускаемых изделий - конденсаторы и резисторы для поверхностного монтажа сегодня уже сопоставимы по размерам с кристаллом соли. Тем не менее пространство на печатной плате или подложке, необходимое для размещения компонентов, не уменьшается с той же скоростью, что и размеры посадочных мест компонентов и расстояние между ними. Для дальнейшего увеличения отношения "функциональность / площадь" требуется совершенно новый подход. Перспективное решение - технология внутреннего монтажа активных и пассивных элементов, которая обеспечивает

НИУ МИЭТ, руководитель УНЦ Института НМСТ,

vdv.vertyanov@gmail.com.

НИУ МИЭТ, доцент Института НМСТ, madcatse@gmail.com.

Mentor, A Siemens Business, директор системных решений,

Per_Viklud@mentor.com.

АО «ЗНТЦ», руководитель центра корпусирования и 3D-сборки микросхем, sidorenko@zntc.ru. резкий рост плотности сборки элементов и позволяет вывести отношение "функциональность / площадь" на совершенно новый уровень.

Концепция технологии берет свое начало еще с 1990-х годов, однако по различным причинам до недавнего времени не была распространена в отрасли. На сегодняшний день технология уже используется в серийном производстве рядом ведущих предприятий, с каждым годом количество компаний, разрабатывающих электронные устройства со встроенными бескорпусными элементами, становится все больше. Согласно оценке Yole Developpement по итогам 2019 года среди высокоплотных технологий сборки и монтажа электроники применение технологии встраивания кристаллов выросло примерно на 49\% по сравнению в 2018 годом [1]

Успешное внедрение новых перспективных технологий и решений на ранних стадиях дает конкурентные преимущества. Поэтому для предприятий электронной промышленности крайне важно узнать больше о технологии внутреннего монтажа элементов, учесть все плюсы и минусы данного подхода, изучить проблемы и пути их решения на этапах проектирования и передачи данных на производство. 


\section{КОНЦЕПЦИЯ ВНУТРЕННЕГО МОНТАЖА ЭЛЕМЕНТОВ И КОНСТРУКТИВНО- ТЕХНОЛОГИЧЕСКИЕ РЕШЕНИЯ}

В современных изделиях теряется грань между электронным компонентом, печатной платой и модулем. Это связано, в первую очередь, с внедрением технологий встраивания в структуру печатной платы пассивных и активных элементов, антенн, теплоотводов и других функциональных элементов электронного изделия. Такое изделие фактически представляет собой гибридную систему или микросборку [2]. Например, микросборка Microsıр от Texas Instruments (рис. 1) содержит встроенный в подложку

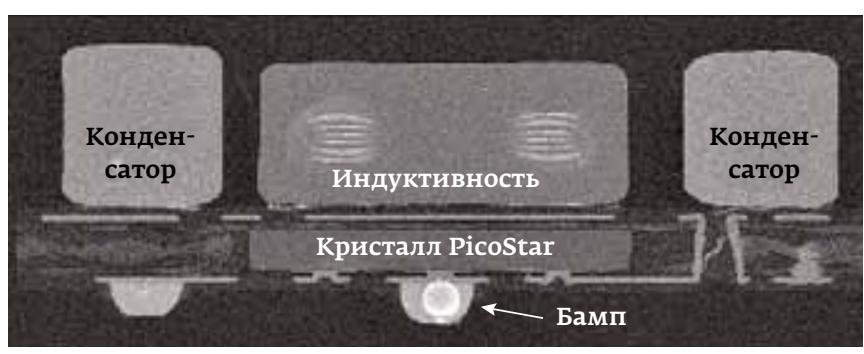

Рис. 1. Структура микросборки MicrosIP от Техаs Instruments, созданной по технологии внутреннего монтажа

Элементы встраиваются в органическую подложку / ядро печатной платы посредством сочетания:

сборки элементов, корпусирования, технологических процессов изготовления печатных плат

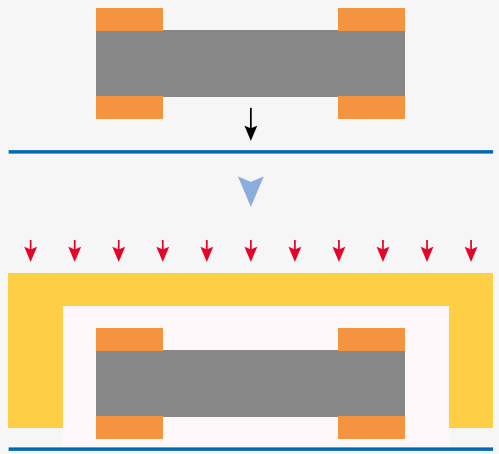

\section{1. Размещение} элемента

2. Прессование / ламинирование

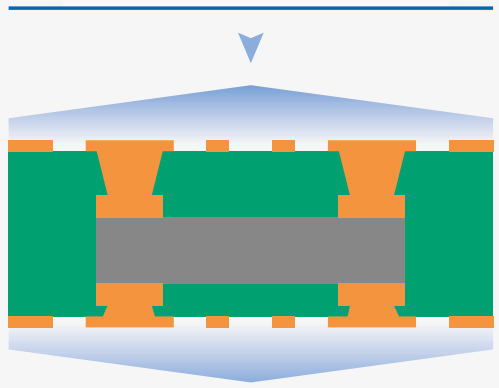

3. Формирование структуры HDI или послойное наращивание по выбору

Рис. 2. Концепция технологии внутреннего монтажа элементов кристалл Pico Star и дискретные компоненты - индуктивность и конденсаторы, установленные методом поверхностного монтажа [3].

Суть технологии заключена в ее названии - встраивание элементов и/или компонентов в коммутационный носитель (печатную плату, подложку корпуса или микросборки). Оригинальность технологии внутреннего монтажа состоит в объединении вместе технологических процессов сборки и монтажа, корпусирования и изготовления печатных плат. На первом этапе активный и / или пассивный элемент размещается и фиксируется с помощью специального адгезива на носителе из металлической фольги. Далее припрессовывается препрег или ламинат (базовый материал), добавляются слои металлизации и формируется топология и межсоединения к встроенным элементам. При необходимости в структуру добавляются последующие $\mathrm{HDI}$-слои методом послойного наращивания [4]. На рис. 2 условно изображена схема данной концепции.

Перспективным направлением для создания сенсорных систем считается встраивание бескорпусных микросхем в гибко-эластичные носители, как, например, в разработке миэТ (рис. 3) [5, 6]. В качестве активных элементов можно
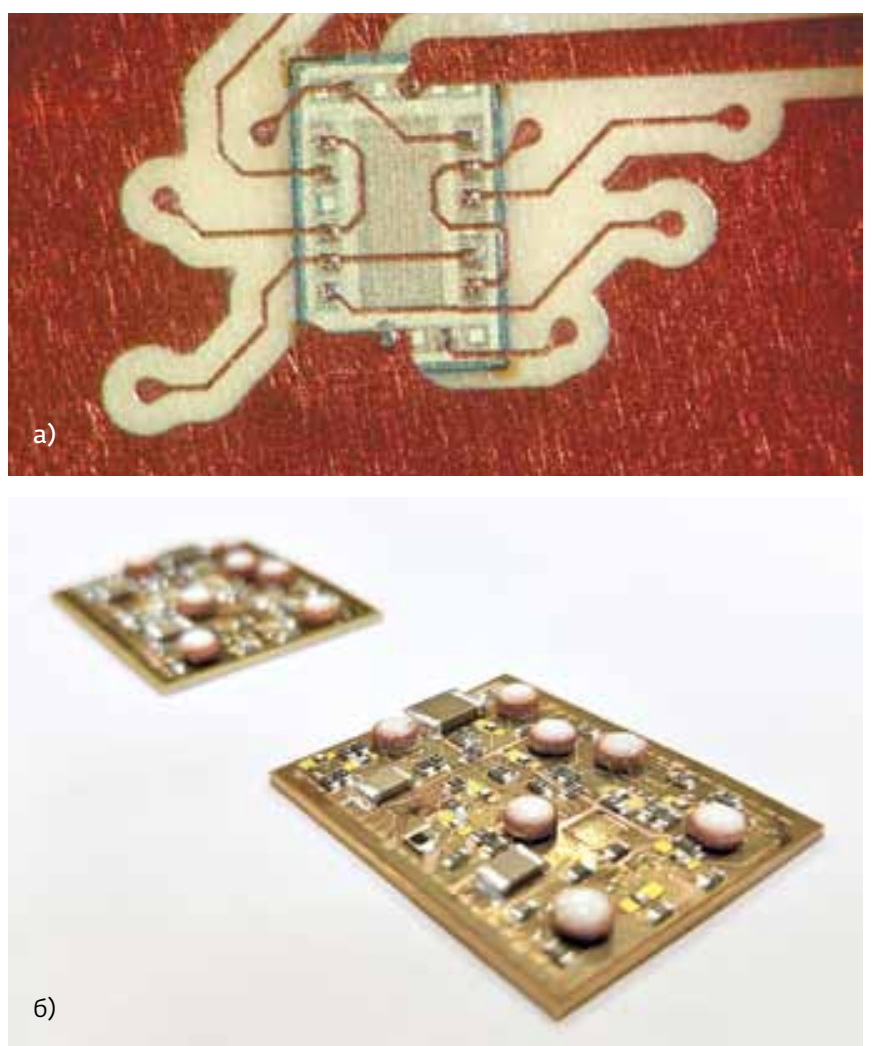

Рис. 3. Микросборка со встроенными бескорпусными микросхемами: а - первый слой коммутации с кристаллом, встроенным в гибко-эластичный носитель; 6 - внешний вид микросборок, изготовленных по технологии внутреннего монтажа $[5,6]$ 
использовать бескорпусные микросхемы, чувствительные элементы МЭМС, МИС СВЧ, ФИС. Пассивные элемен-

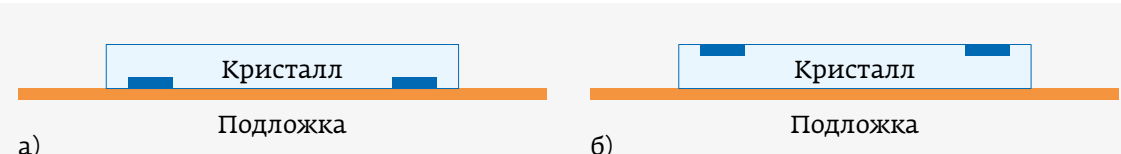
ты встраиваются в подложку в дискретном исполнении или формируются в процессе изготовления коммутационных слоев печатной платы по тонкопленочной или толстопленочной технологии.

В технологиях внутреннего $\mathrm{MOH}^{-}$ тажа кристаллы могут размещаться на носителе активной стороной вниз или вверх в зависимости от выбранного технологического процесса (рис. 4)

существует также решение по сборке кристаллов с контактными площадками, расположенными с двух сторон.

a)

Подложка

б)

Рис. 4. Варианты установки кристалла на подложку: а - лицевой стороной вниз; б - лицевой стороной вверх

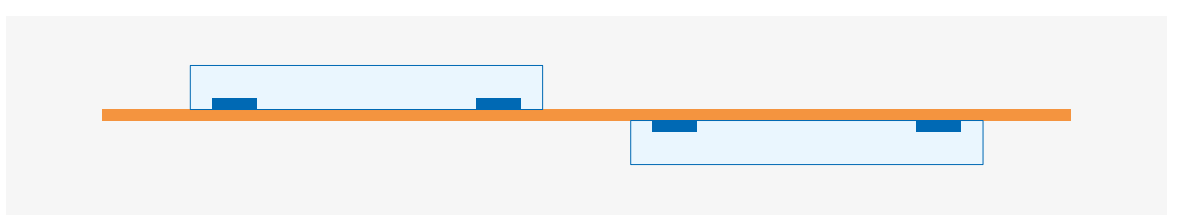

Рис. 5. Кристаллы расположены с двух сторон металлической фольги

Каждый слой металлизации имеет две стороны - верхнюю и нижнюю. В традиционной технологии изготовления подложек элементы и компоненты могут быть размещены на верхней поверхности верхнего слоя или на нижней поверхности нижнего слоя. А когда элемент располагается внутри подложки, можно использовать обе стороны металлической фольги. Это усложняет производство и процесс автоматизированного проектирования электронныхустройств, в частности модуль САПР по работе со слоями платы должен иметь возможность управлять элементами, размещенными в одном и том же месте на одном и том же слое, но ориентированными в разные стороны (вверхи вниз). Рис. 5 иллюстрирует принцип сборки элементов на обеих сторонахслоя металлизации. Верхний кристалл устанавливается лицевой стороной вниз, а нижний кристалл с обратной стороны лицевой стороной вверх.

При изготовлении подложки со встроенными элементами может применяться один из двух основных подходов:

- Chip First - сначала устанавливаются элементы на заготовку подложки, а затем формируются коммутационные слои подложки вокруг них;

- Chip Last - элементы устанавливаются на подложку после формирования на ней всех коммутационныхслоев.

У каждого подхода имеются свои плюсы и минусы. Сторонники подхода Chip Last утверждают, что при варианте Chip First при низком выходе годных кристаллов возникают риски потери работоспособности конечного изделия, так как после сборки они уже не могут быть заменены в случае выявления брака в подложке. Те, кто выбирает подход Chip First, утверждают, что необходимый выход годных можно держать под контролем и производить подложки высокого качества, при этом возможно достичь более высокой плотности монтажа элементов. К тому же отлаженная технология на высокотехнологичном производстве позволяет достичь уровня выхода годных кристаллов свыше 97\%. В обоих вариантах достаточно трудно, а в некоторых случаях даже невозможно, произвести испытания кристаллов перед сборкой. Кристаллы слишком малы, и не все размеры контактных площадок и шаг между ними пригодны для тестового оборудования. Поэтому одна из важных задач для решения данной проблемы - тщательный контроль производственного процесса.

Рассмотрим на примере первый подход - Chip First. В качестве исходной заготовки-носителя может выступать металлическая фольга, фольгированный диэлектрик или коммутационная подложка со сформированной топологией и металлизированными сквозными отверстиями (рис. 6).

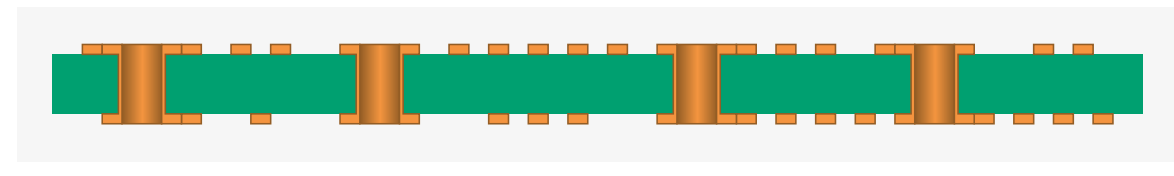

Рис. 6. Исходная заготовка в виде коммутационной подложки с отверстиями и проводящими слоями

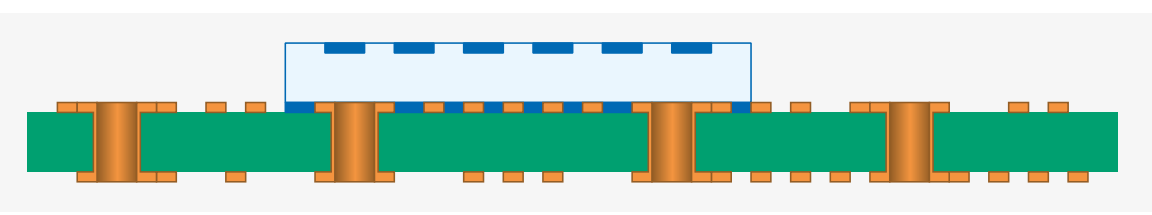

Рис. 7. Кристалл установлен на коммутационную подложку 
Кристалл может быть установлен непосредственно на носитель (рис. 7) или на диэлектрический материал.

Далее диэлектрический материал вместе со следующим проводящим слоем припрессовывается к структуре полученной ранее заготовки (рис. 8).

После герметизации отверстия к контактным площадкам кристалла формируются методом лазерной обработки (рис. 9). Существуют также и другие методы формирования отверстий до контактных площадок кристаллов и обеспечения электрического соединения. При этом у каждой технологии внутреннего монтажа свой собственный метод, самыми известными их которых являются: плазмохимическое травление и вакуумное осаждение; с помощью анизотропной проводящей пленки (АПП); термокомпрессионный монтаж; с помощью проволочных микровыводов.

Следует отметить, что одна лазерная установка для формирования отверстий по производительности эквивалентна примерно 100 установкам проволочного микромонтажа.

Заключительный этап - формирование проводящего слоя и металлизация отверстий (рис. 10).

Во втором подходе, Chip Last, технологический процесс начинается с изготовления коммутационной подложки и формирования диэлектрического слоя с полостью под размещение кристалла (рис. 11).

На следующем этапе производится сборка и монтаж кристалла в полость, например с помощью анизотропной проводящей пленки. Пленка изготавливается из материала, который проводит токтолько в плоскостиZ, а в плоскости X, Ү обладает высоким сопротивлением. В данном примере сборка осуществляется с помощью непроводящей пленки типа NCF. По завершении технологического процесса кристалл устанавливается в полость диэлектрика, выравнивается и фиксируется методом термокомпрессионного соединения (рис. 12).

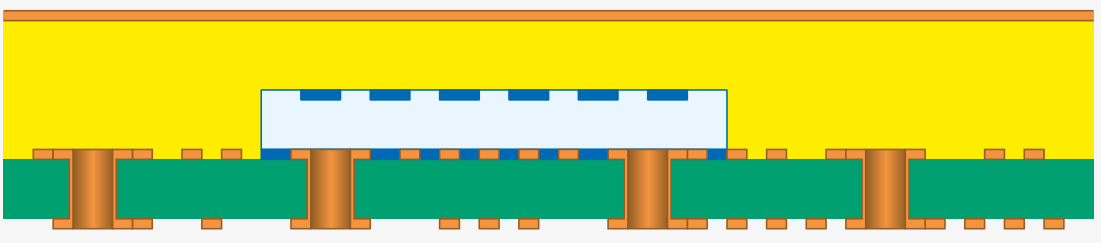

Рис. 8. Кристалл загерметизирован внутри подложки

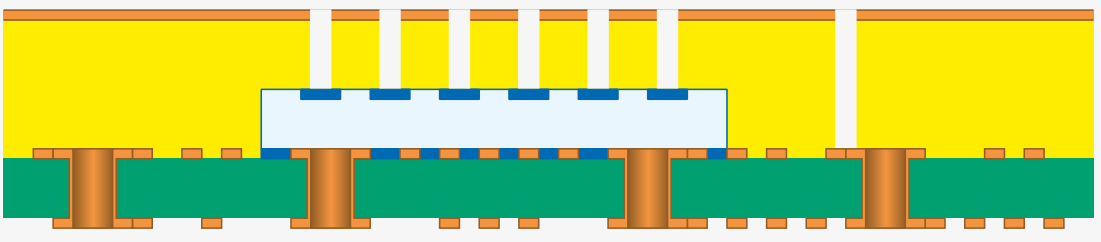

Рис. 9. Структура после формирования отверстий к контактным площадкам кристалла методом лазерной обработки

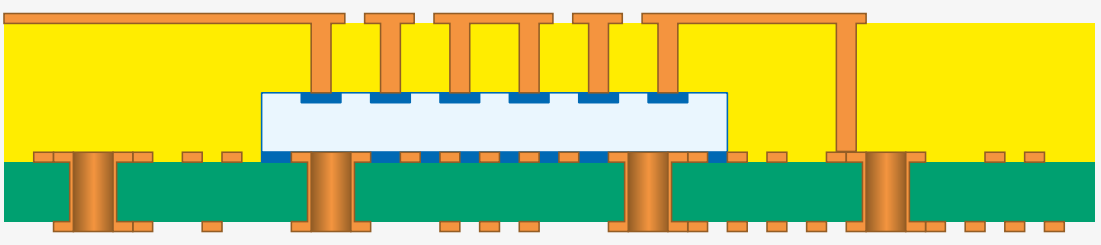

Рис. 10. Структура после формирования топологии проводящего слоя и металлизации отверстий

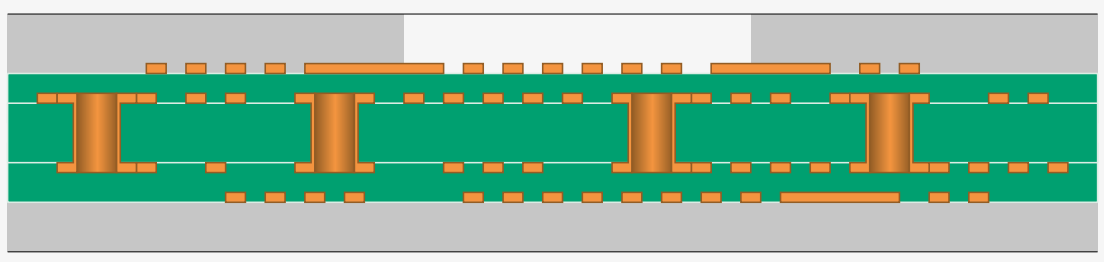

Рис. 11. Структура коммутационной подложки со сформированным диэлектрическим слоем и полостью под размещение кристалла

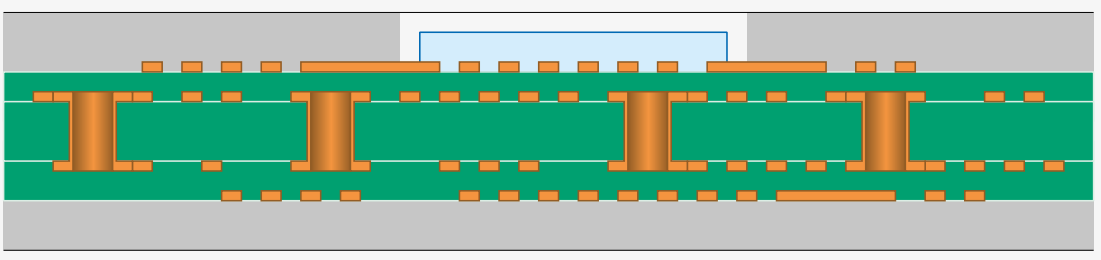

Рис. 12. Структура после термокомпрессионного монтажа кристалла по технологии Chip Last 


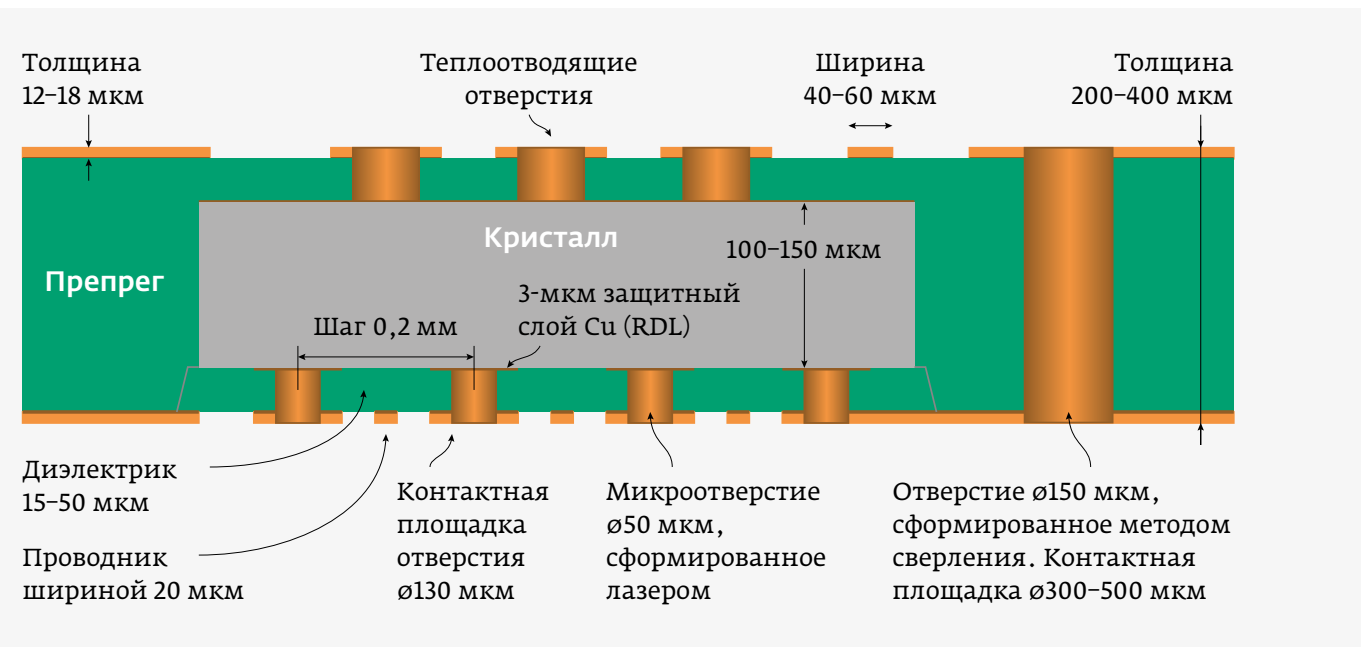

Рис. 13.

Пример структуры фрагмента подложки микросборки со встроенным кристаллом с указанием размеров элементов

На рис. 13 изображен пример структуры фрагмента подложки микросборки со встроенным кристаллом. В данной структуре кристалл расположен внутри диэлектрического основания, а не на слое металлизации. Встраиваемый элемент может быть утонен, например до 150 мкм, при этом предельные размеры могут варьироваться в диапазоне от 5 до 400 мкм. Процесс утонения кристаллов часто необходим, в частности если создается многоуровневая структура встроенных элементов.

\section{ВНЕДРЕНИЕ ТЕХНОЛОГИИ ВНУТРЕННЕГО МОНТАЖА}

Безусловно, внедрение новых технологий всегда связано с определенными рисками. Некоторые из них реальные и требуют особого внимания, другие же только воспринимаются как реальные, потому что вынуждают работать в непривычных условиях. Но на все технологии воздействуют внешние факторы, как со стороны производства, так и со стороны бизнеса. При этом то, насколько хорошо эти факторы соотносятся с конкретным проектом, потребностями бизнеса, потенциалом и ресурсами организации, и зависит решение о принятии или нет данных рисков. Для внедрения технологии внутреннего монтажа существует много веских причин.

Первая причина - это технические факторы. Отношение "функциональность/площадь" резко возрастает. Встроенные элементы имеют гораздо меньшие геометрические размеры (например, толщина кристалла может быть от 50 до 400 мкм), чем поверхностно-монтируемые компоненты в традиционной технологии печатных плат. Соответственно в меньшем объеме можно разместить больше элементов, и это один из важных факторов.

По сравнению с известными современными технологиями сборки и монтажа печатных плат, такими как, например, технология поверхностного монтажа, новая технология монтажа исключает не только процессы корпусирования интегральных схем, но и формирование выводов ИС, внутренних и внешних, а с ними - операции пайки или сварки выводов. Для образования электрического контакта между печатной платой и элементом, вместо пайки и сварки, используется, например, способ наращивания (вакуумное и / или химическое осаждение металлизации) проводников поверх контактных площадок полупроводникового элемента. Такой способ наращивания коммутационных слоев не нуждается в больших внутренних контактных площадках, необходимых в традиционных печатных платах. Это освобождает место под дополнительную разводку и снижает количество слоев. Соответственно, можно достичь более высокой плотности трассировки и уменьшить количество слоев.

Беспаечные и бессварочные методы формирования межсоединений с контактными площадками кристаллов позволяют значительно улучшить электрические параметры изделий, сокращая длину сигнальных и силовых цепей, а также повышая однородность линий передачи сигнала. По сравнению с традиционной технологией производства печатных плат или технологией корпусирования длина цепей при использовании технологии внутреннего монтажа элементов уменьшается до 70\%. При передаче сигнала по более коротким соединениям тратится меньше энергии, поскольку их емкость меньше. Сокращение длины проводников ведет к снижению паразитных емкостей и индуктивностей, к уменьшению сопротивления цепей, что в свою очередь позволяет сократить задержки и уменьшить искажения сигналов. Повышение же однородности линий передачи ведет к уменьшению затухания сигнала, поскольку на пути распространения сигнал встречает меньше границ раздела материалов с различными электрическими свойствами. Указанные свойства межсоединений, получаемые по беспаечному и бессварочному технологическому процессу, подтверждаются моделированием. Например, на рис. 14 показаны результаты моделирования S-параметров для соединения, полученного стандартным поверхностным монтажом, 


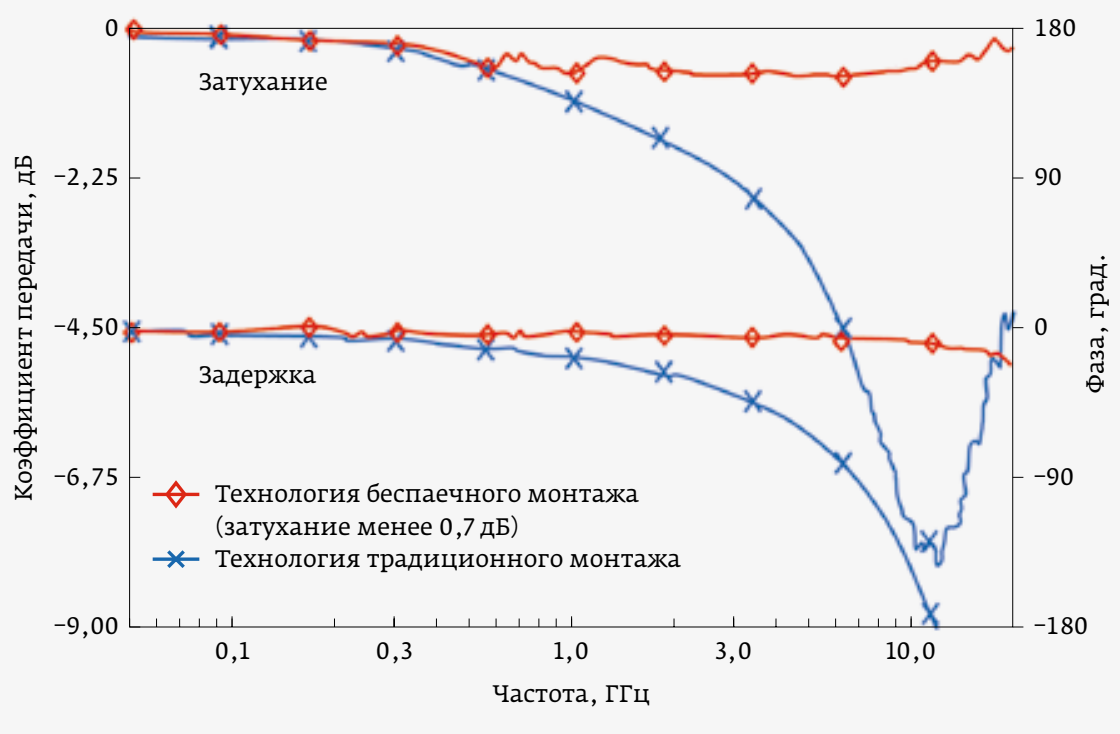

Рис. 14. Результаты электрического моделирования S-параметров для микросборок, созданных с использованием традиционных технологий монтажа и с использованием внутреннего монтажа $[7,8]$

и соединения, полученного по беспаечной и бессварочной технологии [7, 8]. Анализ целостности сигналов для различных технологий внутреннего монтажа проводится в специализированных программных средствах.

Технология предоставляет идеальное решение для теплоотвода. Радиаторы, системы фазовых переходов и даже охладительные микротрубки могут быть размещены прямо внутри конструкции, поверх элементов/компонентов или между ними.

Еще один технический фактор, на который следует обратить внимание - это возможность встраивать различные датчики в подложку. Существует большое количество сенсорных устройств со встроенными датчиками, например датчики скорости и газовых сред, ИК-датчики и радары. Датчики для проведения медицинскиханализов могут быть встроены в электронный модуль, который вживляется в тело человека. Автомобильные датчики сгорания могут быть встроены в цилиндр двигателя. В случае использования других технологий все эти задачи практически невозможно реализовать или же это будет очень дорого.

В дополнение к техническим факторам есть ряд факторов, связанных с бизнес-процессами. Успешное внедрение технологии внутреннего монтажа на производстве может позволить выпустить изделие на рынок раньше основных конкурентов. Примечательно, что производители, использующие технологию внутреннего монтажа элементов, пришли к выводу, что с помощью данной технологии можно сократить расходы по сравнению с традиционной технологией. Этот вывод основан на уменьшении количества технологических операций, материалов и затрат энергии в сравнении с традиционной технологией, что, в свою очередь, связано с объединением производства печатных плат и процессов сборки и монтажа. Переход от технологии поверхностного монтажа корпусных микросхем к новой технологии монтажа бескорпусных микросхем способен значительно снизить затраты на производство электронной аппаратуры и уменьшить экологический вред производств.

Поддержку и развитие технологий внутреннего монтажа осуществляют ведущие мировые компании в данной области, например консорциум TDK и ASE (технология SESUB), AT\&S и UTAC (технология ЕСР), General Electric (технология POL). Совместные усилия предпринимают также производители оборудования, например Siemens, Bosch Daimler, Continental и Thales. Участие крупных производителей оборудования в программах такого рода говорит о больших ожиданиях от технологии в будущем.

Технология внутреннего монтажа подходит для производства широкого спектра изделий разного физического объема и сложности. Области применения включают в себя высоконадежную электронику для военного, аэрокосмического и медицинского применения, а также потребительские устройства. Ниже представлены некоторые из возможных приложений:

- датчики скорости / газовых сред и охранные датчики;

- сенсорные системы, модули РЛС, устройства управления питанием, устройства для навигации и наведения, устройства беспроводной связи;

- компоненты и модули для сотовых телефонов;

- оборудование базовых станций и портативные устройства с РЧ-, GPS-, WLAN-модулями;

- изделия медицинской техники, в том числе имплантируемые устройства, такие как датчики для химического анализа, устройства автоматической подачи лекарств и имплантируемые системы жизнеобеспечения (например, кардиостимуляторы и дефибрилляторы); внешние устройства (например, слуховые аппараты);

- устройства автоэлектроники: встроенные в двигатель устройства управления, системы безопасности, интеллектуальные системы круиз-контроля, навигационные и информационно-развлекательные системы. 
Таблица 1. Примеры конструкций микросистем со встроенными кристаллами (по данным AT\&S)

\begin{tabular}{|c|c|c|c|c|}
\hline $\begin{array}{l}\text { Область } \\
\text { применения }\end{array}$ & $\begin{array}{c}\text { Габариты } \\
\text { микроси- } \\
\text { стемы, } \\
\text { мм² }^{2}\end{array}$ & $\begin{array}{c}\text { Умень- } \\
\text { шение } \\
\text { размеров, } \\
\text { \% X, Y }\end{array}$ & $\begin{array}{c}\text { Структура } \\
\text { микро- } \\
\text { системы }\end{array}$ & Особенности и преимущества \\
\hline $\begin{array}{l}\text { Преобразователи } \\
\text { напряжения }\end{array}$ & 7 & 40 & & $\begin{array}{l}\text { Один из самых малогабаритных преобразователей } \\
\text { постоянного напряжения } 600 \text { мА }\end{array}$ \\
\hline $\begin{array}{l}\text { Устройства управления } \\
\text { питанием }\end{array}$ & 20 & 40 & & $\begin{array}{l}\text { Вертикальная сборка кристаллов для устройств } \\
\text { управления зарядом литий-ионных аккумуляторов }\end{array}$ \\
\hline $\begin{array}{l}\text { Высоконадежные } \\
\text { носители информации }\end{array}$ & 20 & 30 & & $\begin{array}{l}\text { Интегрированные модули - дискретные пассивные } \\
\text { элементы, смонтированные по технологии еWLP }\end{array}$ \\
\hline $\begin{array}{l}\text { Датчики на основе } \\
\text { МЭМС }\end{array}$ & 5 & $>50$ & & МЭМС-устройства с наименьшими размерами \\
\hline $\begin{array}{l}\text { Устройства } \\
\text { для портативных ТВ }\end{array}$ & 20 & 50 & & $\begin{array}{l}\text { Дискретный компонент в качестве мобильного } \\
\text { приемника }\end{array}$ \\
\hline $\begin{array}{l}\text { Датчики } \\
\text { идентификации }\end{array}$ & 60 & $>30$ & & Интегрированный биометрический сенсор \\
\hline Сенсорные системы & 60 & 50 & & $\begin{array}{l}\text { Кристалл расположен контактными площадками } \\
\text { вверх в микросборке }\end{array}$ \\
\hline $\begin{array}{l}\text { Устройства для телеком- } \\
\text { муникационных систем }\end{array}$ & 20 & 40 & & $\begin{array}{l}\text { Элементы размещены друг над другом для достиже- } \\
\text { ния наименьших размеров }\end{array}$ \\
\hline
\end{tabular}

В табл. 1 представлены примеры существующих конструкций микросистем со встроенными кристаллами.

Усовершенствованные конструкции изделий могут содержать проводящие элементы, например металлические покрытия и экраны, покрывающие локальные зоны или полностью всю микросистему, микросборку. Экраны предназначены для блокирования помех от источников электромагнитного излучения. Кроме того, используя металлические покрытия, можно получить почти герметичные конструкции. Технология также подойдет для применения в оптоэлектронной промышленности, например для интеграции фотооптических каналов передачи данных

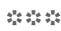

Во второй части статьи рассмотрим особенности проектирования и организации производства микросистем со встроенными элементами, а также пример реализации проекта модуля, выполненного с помощью САПР компании Mentor, A Siemens Business.

\section{ЛИТЕРАТУРА}

1. Status of the Advanced Packaging Industry, Yole Développement, 2019. - http://www.yole.fr/iso_upload/ News/2019/PR_ADVANCED_PACKAGING_MarketOverview_ YOLE_July2019.pdf.
2. Вертянов Д. В., Сикоев В.Г., Горюнова Е.П., Тимошенков С.П. Комплексное проектирование микросистем на печатных платах в САПР Mentor Graphics. Учеб. пособие. ч. 1: Центральная библиотека Library Manager / Министерство образования и науки РФ, НИУ «МИЭТ»; под ред. Тимошенкова С.П. - М.: МИЭТ, 2019. С. 172.

3. Lu D. Materials for advanced packaging: second edition / D. Lu, C. P.Wong - Springer, 2017. P. 974.

4. Happy Holden. The HDI Handbook First Edition. Mentor Graphics Corporation. 2009. C. 617.

5. Вертянов Д. В., Сидоренко В.Н., Тимошенков С.П., Ковалёв А. А. Перспективные конструктивно-технологические решения для производства "систем в корпусе» // Технологии в электронной промышленности. 2019. № 4. С. 60-64.

6. Вертянов Д. В., Сидоренко В.Н, Беляков И.А. Особенности процессов сборки бескорпусных микросхем в технологии изготовления микросборок на основе внутреннего монтажа // НАНОИНДУСТРИЯ. 2020. С. 396-406.

7. Tuominen R. Embedded Components in PCB / R. Tuominen, Imbera Electronics Oy. - http://pwrsocevents.com/wp-content/ uploads/2008-presentations/Invited\%20Talk\%20S6x7\%20-\%20 Risto\%20Tuominen\%20-\%20Embedded\%20Components\%20 in\%20PCB.pdf.

8. Integrated Module Board Technology: Manufacturing Process and Electrical Properties of IMB connection, Palm, Petteri, Tuominen, Advancing Microelectronics, vol 31. no 1. 
МЕЖАУНАРОАНАЯ ВЫСТАВКА

$x \rightarrow$
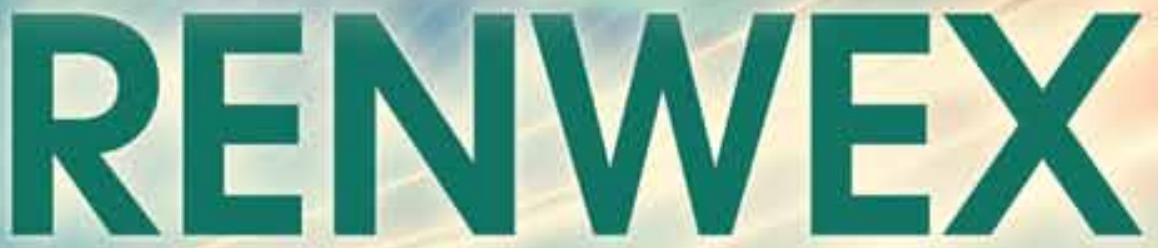

“Возобновляемая энергетика и электротранспорт"

МеЖАУНарОАНЫЙ ФОрУМ “ВозобновАяемая энергетика А^я регионального развития"

\section{0-22 ОКТЯБРЯ 2020}

Россия, Москва, ЦВК "ЭКСПОЦЕНТР", павильон №3

КЛЮЧЕВЫЕ НАПРАВЛЕНИЯ:

(88. Развитие розничного рынка ВИз

и необходимых технических решений

(E) Нормативное регулирование ВИэ

(2) Использование ВИЭ для энергоснабжения удаленных и изолированных потребителей

(9) Использование биотоплива и утилизация отходов

(8) Международный опыт развития возобновляемой энергетики

(2) Цифровизация современной энергетики

Р. Развитие систем накопления энергии для промышленных потребителей и домохозяйств

\$2 Развитие электротранспорта и сопутствующей инфраструктуры

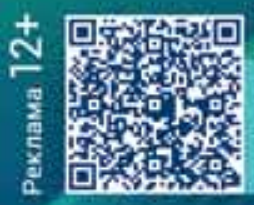

\section{www.renwex.ru}

89

A минпромторг euro

eyro
solde

:

A

B 셰드를

IOA Datpointom 